Check for updates

Cite this: RSC Adv., 2018, 8, 3014

Received 21st September 2017 Accepted 26th December 2017

DOI: $10.1039 / c 7 r a 10489 h$

rsc.li/rsc-advances

\section{Gold, silver and nickel nanoparticle anchored cellulose nanofiber composites as highly active catalysts for the rapid and selective reduction of nitrophenols in water $\dagger$}

\author{
Mayakrishnan Gopiraman, (DD a Dian Deng, (DD ${ }^{\mathrm{b}}$ Somasundaram Saravanamoorthy, ${ }^{\mathrm{c}}$ \\ IIl-Min Chung (D) ${ }^{* a}$ and Ick Soo Kim (D) *b
}

Highly active metal nanoparticle (MNP) supported cellulose nanofiber (CNF) composites (Au/CNF, Ni/CNF and $\mathrm{Ag} / \mathrm{CNF}$ ) were prepared for the reduction of 4- and 2-nitrophenols (4-NP and 2-NP) in water. Transmission electron microscopy (TEM) images showed that the ultrafine nanoparticles ( $\mathrm{Au}, \mathrm{Ni}$ and $\mathrm{Ag}$ NPs) were uniformly deposited on CNFs surface. The content of $\mathrm{Au}(9.7 \mathrm{wt} \%)$, Ni (21.5 wt\%) and $\mathrm{Ag}$ (22.6 wt\%) in Au/CNF, Ni/CNF and Ag/CNF respectively was determined by energy dispersive spectroscopy (EDS) and inductive coupled plasma-mass spectroscopy (ICP-MS) analysis. The chemical state of the MNPs in Au/CNF, Ni/CNF and Ag/CNF was determined by X-ray photoelectron spectroscopy (XPS) and X-ray diffraction (XRD). The significant metal-support interaction was studied by means of XPS. The $\mathrm{Au} / \mathrm{CNF}, \mathrm{Ni} / \mathrm{CNF}$ and Ag/CNF demonstrated excellent catalytic activity towards the reduction of nitrophenols to aminophenols in water. To our delight, even a very low amount of catalyst was also found to be good enough to achieve 100\% reduction of 4- and 2-NP with a higher reaction rate (within $5 \mathrm{~min})$. The best rate constant $\left(k_{\mathrm{app}}\right)$ values were determined for the cellulose nanocomposites. To the best our knowledge, Au/CNF, Ni/CNF and Ag/CNF are the most efficient nanocatalysts for the reduction of 4- and 2-NP reported to date. The catalytic performance of Au/CNF, Ni/CNF and Ag/CNF was compared with previously reported results. A possible mechanism has been proposed for these catalytic systems.

\section{Introduction}

Cellulose nanocomposites have received substantial consideration both in industry and academia due to their enhanced physicochemical properties, unique structural features and wide range of applications. ${ }^{1}$ Particularly, the cellulose nanocomposites produced via the electrospinning (ES) method have gained much attention due to their huge surface area, easy handling and exceptional mechanical properties. ${ }^{2,3}$ The role of cellulose nanocomposites in applications such as catalysis, sensors, filters, energy, separators and biomedicine is

${ }^{a}$ Department of Applied Bioscience, College of Life \& Environment Science, Konkuk University, 120 Neungdong-ro, Gwangjin-gu, Seoul 05029, South Korea. E-mail: imcim@konkuk.ac.kr; illminchung@gmail.com

${ }^{b}$ Nano Fusion Technology Research Group, Division of Frontier Fibers, Institute for Fiber Engineering (IFES), Interdisciplinary Cluster for Cutting Edge Research (ICCER), Shinshu University, Tokida 3-15-1, Ueda, Nagano prefecture, 386-8567, Japan.E-mail: kimicksoo.gr@gmail.com

${ }^{c}$ Department of Chemistry, National Institute of Technology, Tiruchirappalli 620015 , India

$\dagger$ Electronic supplementary information (ESI) available: FT-IR spectra, UV-Vis spectra, SEM-EDS elemental analysis, ICP-MS results and UHPLC chromatograms. See DOI: 10.1039/c7ra10489h significant. ${ }^{4}$ Applications of cellulose nanofiber as a metal NP support have attracted a lot of interest in recent years. ${ }^{5}$ Metal NP supported cellulose nanofibers have been used for various applications such as in water purification and separation, sensors, antibacterial treatment, biological and environmental analysis, and catalysis. For instance, Son et al. ${ }^{6}$ prepared a cellulose acetate nanofiber/Ag NP nanocomposite and it was used for its antimicrobial activity. Zhang and co-workers ${ }^{7}$ reported biotemplated synthesis of AuNPs/cellulose nanofiber composites. They found that the prepared nanofiber composites showed excellent results in biosensing applications. Similarly, Ag nanoparticle-immobilized cellulose nanofibril films were prepared and it was studied for environmental conservation by Ramaraju et al. ${ }^{8}$ Very recently, our group has prepared Ag and Ru NPs immobilized cellulose nanofiber composites. We found that the nanocomposites have superior catalytic activity towards the aerobic oxidation of alcohol and $a z a$-Michael reaction. ${ }^{9}$ In spite of the advantages, a very limited number of works published in the literature on the cellulose nanofiber composites for catalytic applications. Hence, the present study is focused on the cellulose nanocomposites for catalytic applications. 
Nitrophenols including 4-nitrophenol (4-NP) and 2-nitrophenol (2-NP) are a common organic pollutant that occurs in industrial wastewater. ${ }^{10}$ Generally, the nitrophenols are very stable in wastewater and often cause environmental pollution due to its carcinogenesis, hepatotoxicity and mutagenesis. ${ }^{11}$ Hence, the removal of nitrophenols from wastewater is always an important issue. Traditionally, the nitrophenols were removed from wastewater by several methods including electrocoagulation, adsorption, photocatalytic degradation, microbial degradation, electrochemical treatment, electro-Fenton method, electrocoagulation, and so on. ${ }^{12}$ However, recently, the conversion of waste nitrophenols into valuable compounds, aminophenols, has gained vast attention. ${ }^{13}$ The aminophenols are very useful in various applications such as photographic developer, corrosion inhibitor, anticorrosion-lubricant, analgesic and antipyretic drugs. ${ }^{14}$ Commonly, the metal NPs are dispersed onto solid matrices to achieve better performance and easy recovery. Common solid matrices such as carbon, silica, titania, alumina, magnesia, and zirconia and etc., are often used to prepare the heterogeneous metal NPs catalysts. ${ }^{15}$ Due to unique and facile surface modification, the cellulose nanofiber can be an efficient solid support for the controlled immobilization of metal NPs. ${ }^{16,17}$ So far, supported $\mathrm{Au}, \mathrm{Ag}$ and Ni NPs are found to be the most efficient catalyst for the conversion of nitrophenols to aminophenols. ${ }^{13}$ We presume that the $\mathrm{Au}, \mathrm{Ag}$ and Ni NPs supported cellulose nanocomposite would show an excellent activity towards to the reduction of 2and 4-NP. Our aim is to use cellulose nanocomposites as catalyst for the conversion of nitrophenols to aminophenols. To our delight, this is the first report on the metal-based cellulose nanofiber composite for the nitrophenol reduction. Herein, we prepared $\mathrm{Ag}, \mathrm{Au}$ and $\mathrm{Ni}$ NPs supported cellulose nanofiber composite $(\mathrm{Ag} / \mathrm{CNF}, \mathrm{Au} / \mathrm{CNF}$ and $\mathrm{Ni} / \mathrm{CNF})$. The resultant $\mathrm{Ag} /$ $\mathrm{CNF}, \mathrm{Au} / \mathrm{CNF}$ and $\mathrm{Ni} / \mathrm{CNF}$ was used for the reduction of 2and 4-NP.

\section{Experimental section}

\section{Materials}

Gold(III) chloride $\left(\mathrm{AuCl}_{3}, 99.9 \%\right)$, silver(I) nitrate $\left(\mathrm{AgNO}_{3}\right.$, $\geq 99.0 \%$ ), nickel(II) chloride $\left(\mathrm{NiCl}_{2}, 99.9 \%\right)$, sodium hydroxide ( $\mathrm{NaOH}, 99.9 \%)$, sodium chloroacetate $\left(\mathrm{ClCH}_{2} \mathrm{COONa}, \geq 98 \%\right)$, cellulose acetate (CA, 39.8\% acetyl content, $\left.M_{\mathrm{w}}=30 \mathrm{kDa}\right)$, acetone ( $\geq 99.9 \%$ ), $N, N$-dimethylformamide (DMF, 99.7\%), sodium borohydride $\left(\mathrm{NaBH}_{4}, \geq 98.0 \%\right)$ and nitrophenols $(\geq 99 \%)$ were purchased from Wako Pure Chemicals, Japan or Sigma-Aldrich, and used as received.

\section{Preparation of cellulose nanofiber composites}

The anionic cellulose nanofiber (m-CNFs) was prepared according to our previous report. ${ }^{9}$ Initially, $18 \mathrm{wt} \%$ of cellulose acetate solution was prepared using acetone/DMF mixture $(3: 2$ ratios) and it was electrospun under electric field of $12 \mathrm{kV}$ to obtain cellulose acetate nanofibers (CANFs). The resultant CANFs was deacetylated using $0.05 \mathrm{M}$ of $\mathrm{NaOH}$ to produce regenerated cellulose nanofibers (CNFs). Subsequently, soda cellulose (Na-CNFs) was produced from CNFs by dipping it into $1.5 \mathrm{M} \mathrm{NaOH}$ solution for $5 \mathrm{~min}$. Then, the Na-CNFs were dipped into a $1.0 \mathrm{M} \mathrm{ClCH}_{2} \mathrm{COONa}$ solution for $6 \mathrm{~h}$ to obtain anionic cellulose nanofiber (m-CNFs).

As shown in Fig. 1a, the m-CNFs were used to prepare the cellulose nanofiber composites (Au/CNF, Ni/CNF and $\mathrm{Ag} / \mathrm{CNF}$ ). A simple wet reduction method using $\mathrm{NaBH}_{4}$ as a reducing agent was adopted for this purpose. In a typical preparation of $\mathrm{Au} /$ CNFs, $100 \mathrm{mg}$ of m-CNF was dipped into a $100 \mathrm{~mL}$ of aqueous $\mathrm{AuCl}_{3}$ solution at $60^{\circ} \mathrm{C}$ for $24 \mathrm{~h}$, followed by gentle washing with distilled water to remove the excess $\mathrm{AuCl}_{3}$. The resultant wet mat was treated with $\mathrm{NaBH}_{4}(1 \mathrm{mM}, 20 \mathrm{~mL})$ at $25{ }^{\circ} \mathrm{C}$ for $15 \mathrm{~min}$. Similarly, the $\mathrm{Ag} / \mathrm{CNF}$ and $\mathrm{Ni} / \mathrm{CNF}$ were prepared by using $\mathrm{AgNO}_{3}$ and $\mathrm{NiCl}_{2}$ as precursor $(100 \mathrm{~mL}, 0.5 \mathrm{mmol})$. Finally, the obtained $\mathrm{Au} / \mathrm{CNF}, \mathrm{Ni} / \mathrm{CNF}$ and $\mathrm{Ag} / \mathrm{CNF}$ nanofiber composites were washed with distilled water and air dried.

\section{Characterization}

Electrospinning was carried out by using a high-voltage power supply (Har-100*12, Matsusada Co., Tokyo) as the source of electric field, capable of generating voltages up to $100 \mathrm{kV}$. Transmission electron microscope (TEM) was performed on JEM-2100 JEOL Japan with accelerating voltage of $120 \mathrm{kV}$. Scanning electron microscope-energy dispersive spectrum (SEM-EDS, Hitachi, model-3000H) was used to determine the metal content in nanocomposites. Wide angle X-ray diffraction (WAXD) patterns were recorded on Rotaflex RTP300, Rigaku.Co., Japan. Nickel-filtered $\mathrm{Cu} \mathrm{K} \alpha$ radiation was used for the measurements, along with an angular range of $10<2 \theta<50^{\circ}$. Fourier transform infrared (FT-IR) spectra were taken out by using IR Prestige-21, Shimadzu, Japan. X-ray photoemission spectra (XPS) were recorded on Kratos Axis-Ultra DLD model instrument. Ultraviolet-visible (UV-vis) spectra were recorded in $3 \mathrm{~cm}$ path length quartz cell on a Shimadzu UV-2600 spectrophotometer. The reductive products (2- and 4-aminophenol) were further confirmed by ultra high performance liquid chromatography (Thermo UHPLC electron corporation, accucore C18 column, solvent system water : methanol $30: 70$ ratio) at $254 \mathrm{~nm}$ wavelength.

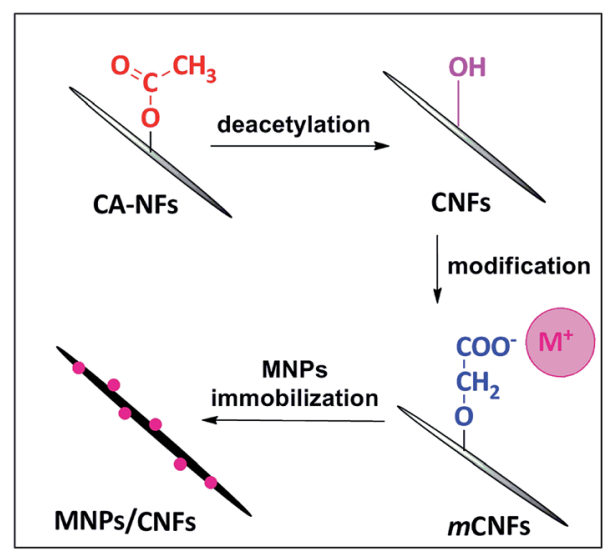

Fig. 1 Illustration for the preparation of MNPs/CNFs. 


\section{Reduction of 4- and 2-nitrophenol}

A 40 or $80 \mu \mathrm{L}$ of aqueous nitrophenol solution $(0.01 \mathrm{M})$ was mixed with $4 \mathrm{~mL}$ freshly prepared $\mathrm{NaBH}_{4}$ solution $(0.01 \mathrm{M})$. To the above mixture, particular amount of Au/CNFs, Ni/CNFs and $\mathrm{Ag} / \mathrm{CNFs}$ was added and stirred well. At a given reaction time, the UV-Vis absorption spectra were recorded within the wavelength range of 250-600 $\mathrm{nm}$. The rate constants of the reduction reaction were calculated by measuring the peak intensity evolution every minute at wavelengths of $400 \mathrm{~nm}$ and $416 \mathrm{~nm}$ for 4-NP and 2-NP, respectively.

\section{Results and discussion}

\section{Characterization of $\mathrm{Au} / \mathrm{CNF}, \mathrm{Ni} / \mathrm{CNF}$ and $\mathrm{Ag} / \mathrm{CNF}$ composites}

In a typical preparation of cellulose nanofibers, cellulose acetate nanofibers (CANFs) were prepared from solution was prepared by electrospinning method. The electrospun CANFs were deacetylated to obtain regenerated cellulose nanofibers (CNFs). Subsequently, the surface of CNFs was chemically modified with anionic group $\left(\mathrm{O}-\mathrm{C}=\mathrm{O}^{-}\right)$(Fig. 1). The successful conversion of CANFs to m-CNFs was confirmed by FTIR. The FT-IR spectrum of CANFs (Fig. $\mathrm{S} 1 \dagger$ ) showed three intense peaks at $1730(\mathrm{C}=\mathrm{O}), 1373\left(\mathrm{C}-\mathrm{CH}_{3}\right)$ and $1223 \mathrm{~cm}^{-1}(\mathrm{C}-\mathrm{O}-\mathrm{C})$, whereas, after deacetylation, the $\mathrm{C}=\mathrm{O}$ absorption at $1730 \mathrm{~cm}^{-1}$ completely disappeared. ${ }^{18}$ In addition, a new peak at $3400 \mathrm{~cm}^{-1}$ (hydroxyl, -OH) was noticed. The FTIR spectrum of m-CNFs showed two new peaks at $1572\left(-\mathrm{COO}^{-}\right)$and $1611 \mathrm{~cm}^{-1}(\mathrm{C}-$ $\mathrm{CH}_{2}$ ). The result clearly shows the successful surface modification of CNFs. The resultant modified cellulose nanofiber (mCNFs) was used as a support for the immobilization of metal nanoparticles ( $\mathrm{Au}, \mathrm{Ag}$ and Ni NPs). In fact, the presence of anionic group $\left(\mathrm{O}-\mathrm{C}=\mathrm{O}^{-}\right)$would act as an anchoring sites for the metal nanoparticles. ${ }^{19}$ In addition, the anionic groups can form a coordination type of bonding with metal ions, which facilitate the formation of ultrafine nanoparticles with very fine dispersion on the surface of the cellulose nanofibers.

The excellent surface morphology of the nanofiber composites (Au/CNF, Ni/CNF and Ag/CNF) was confirmed by the TEM images (Fig. 2). The results showed that the metal nanoparticles are uniformly dispersed with good adhesion on the CNFs surface. Moreover, the magnified TEM images (Fig. 2c, g and k) of the nanofiber composites confirmed that the metal nanoparticles are attached on the surface of the m-CNFs. In order to calculate the average size of the nanoparticles, fifty individual nanoparticles were chosen and the size was measured. The histogram of nanoparticles diameter distribution for $\mathrm{Ag}$, Au and $\mathrm{Ni}$ NPs has been presented in Fig. 2. The average diameter of Ag, $\mathrm{Au}$ and Ni NPs was calculated to be 17.3, 10.5 and $22.5 \mathrm{~nm}$ respectively. The surface area per unit mass $(S)$ of metal nanoparticles was calculated by using the equation $S=6000 /(\rho \times d)$, where $\rho$ is the density of metal and $d$ is the average diameter of metal nanoparticles. ${ }^{15}$ The surface area per unit mass of $\mathrm{Au}$ in $\mathrm{Au} / \mathrm{CNF}, \mathrm{Ni}$ in $\mathrm{Ni} / \mathrm{CNF}$ and $\mathrm{Ag}$ in $\mathrm{Ag} / \mathrm{CNF}$ was calculated to be 29.6, 29.9 and $33.1 \mathrm{~m}^{2} \mathrm{~g}^{-1}$ respectively. The elemental content of the nanofiber composites were determined by SEM-EDS and ICP-MS analysis. Fig. 3 shows the representative SEM, EDS and corresponding elemental mapping of $\mathrm{Au} / \mathrm{CNF}, \mathrm{Ni} / \mathrm{CNF}$ and $\mathrm{Ag} /$ CNF. In order to determine the factual metal content in the nanocomposites, three different areas where choose to take EDX and the average metal content was calculated (see Table S1
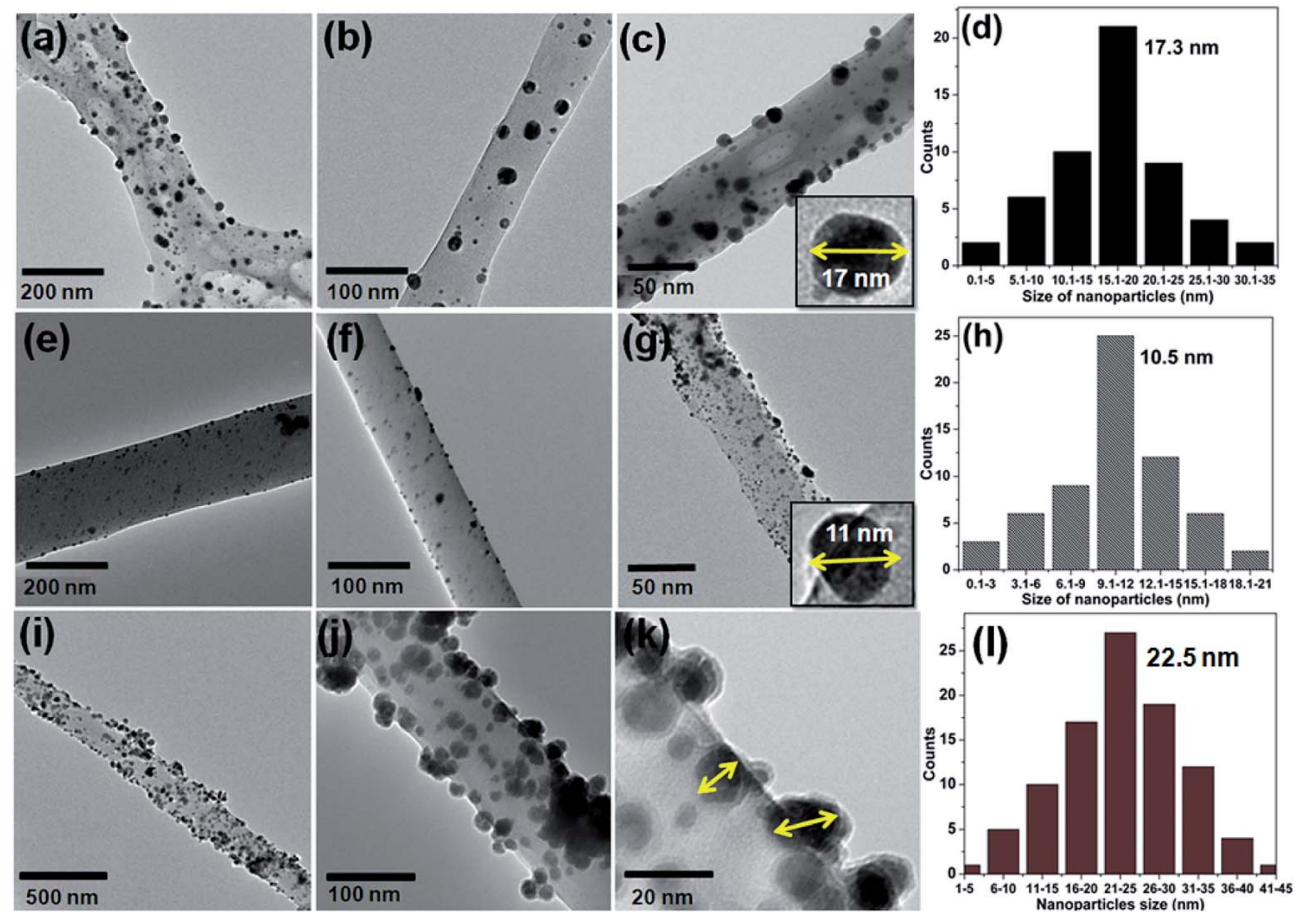

Fig. 2 TEM images of ( $(a-c) A g / C N F,(e-g) A u / C N F$ and (i-k) Ni/CNFs); the histogram of nanoparticles diameter distribution for (d) Ag NPs, (h) Au NPs and (l) Ni NPs. 

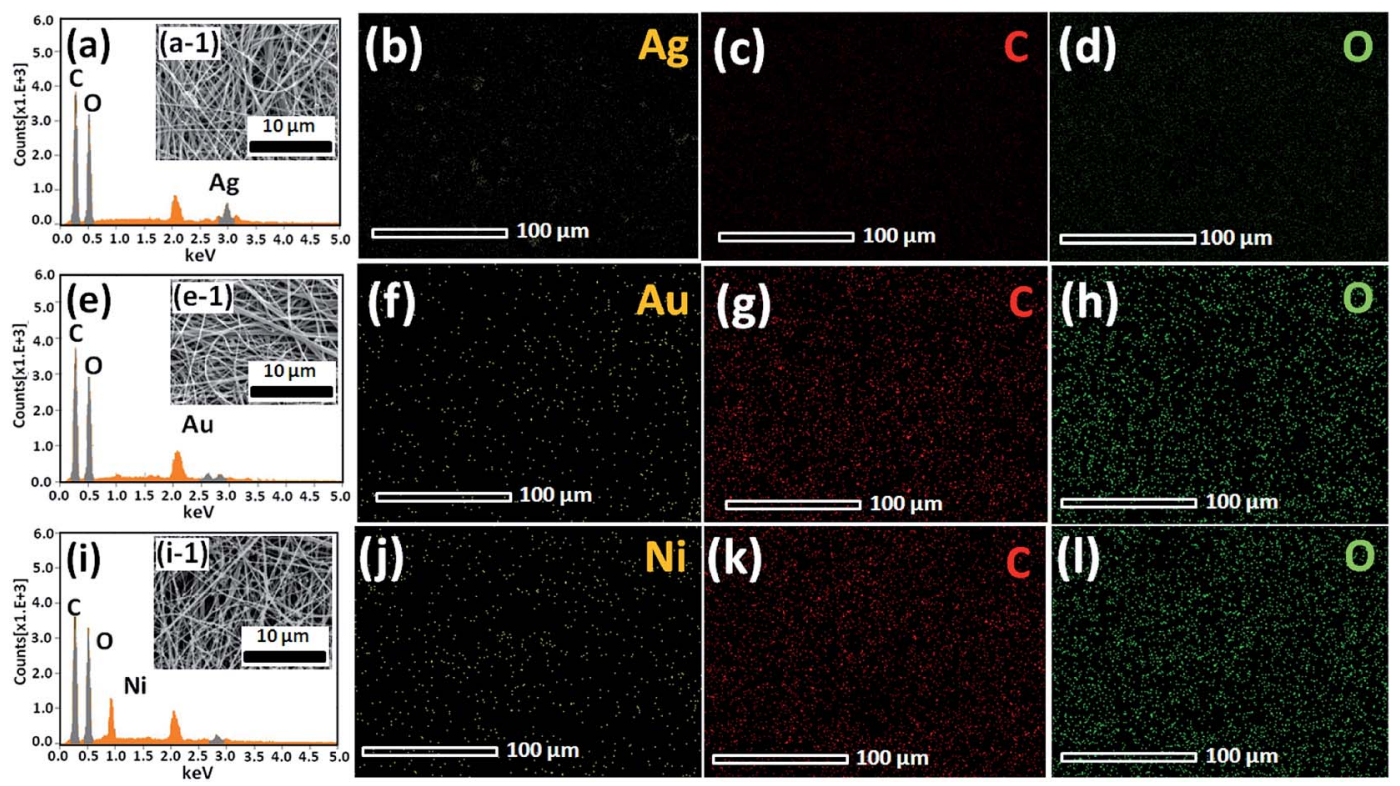

Fig. 3 SEM images, EDS spectra, and corresponding elemental mapping of (a, a-1, b, c and d) Ag/CNF, (e, e-1, f, g, h) Au/CNF and (i, i-1, j, k and l) $\mathrm{Ni} / \mathrm{CNF}$.

in $\mathrm{ESI} \dagger)$. The average content of $\mathrm{Au}(9.7 \mathrm{wt} \%), \mathrm{Ni}(21.5 \mathrm{wt} \%)$ and $\mathrm{Ag}$ (22.6 wt\%) in $\mathrm{Au} / \mathrm{CNF}, \mathrm{Ni} / \mathrm{CNF}$ and $\mathrm{Ag} / \mathrm{CNF}$ was determined by EDS analysis. Similarly, the ICP-MS results confirmed the metal content of $9.45(\mathrm{Au}), 21.45(\mathrm{Ni})$ and $22.94 \mathrm{wt} \%(\mathrm{Ag})$ was determined for the $\mathrm{Au} / \mathrm{CNF}, \mathrm{Ni} / \mathrm{CNF}$ and $\mathrm{Ag} / \mathrm{CNF}$ nanocomposites respectively. The elemental mapping reveals the homogeneous dispersion of metal nanoparticles in the nanofiber composites (Fig. 3).

Chemical state of $\mathrm{Ag}$ in $\mathrm{Ag} / \mathrm{CNF}, \mathrm{Au}$ in $\mathrm{Au} / \mathrm{CNF}$ and $\mathrm{Ni}$ in $\mathrm{Ni} /$ CNF was confirmed by XRD and XPS analysis. Fig. 4 depicts XRD patterns of $\mathrm{Ag} / \mathrm{CNF}, \mathrm{Au} / \mathrm{CNF}$ and $\mathrm{Ni} / \mathrm{CNF}$. The XRD pattern of $\mathrm{Ag} / \mathrm{CNF}$ showed Bragg reflections with $2 \theta$ values of $38.03^{\circ}$, $46.18^{\circ}, 63.43^{\circ}$ and $77.18^{\circ}$ which can be indexed to (1 111$),\left(\begin{array}{lll}2 & 0 & 0\end{array}\right)$, (2 $\left.2 \begin{array}{ll}2 & 0\end{array}\right)$ and ( $\left.\begin{array}{lll}3 & 1 & 1\end{array}\right)$ planes of metallic Ag (JCPDS file no. 87-0720). ${ }^{20}$ Alike, four sharp diffraction peaks at around $2 \theta=38.2^{\circ}, 2 \theta=$ $44.4^{\circ}, 2 \theta=64.6^{\circ}$ and $2 \theta=77.6^{\circ}$ correspond to (111), (200), (220), (311) and (222) facets respectively, indicating the metallic form of $\mathrm{Au}$ in $\mathrm{Au} / \mathrm{CNF}$ (JCPDS file no. 04-0784). ${ }^{21}$ The XRD pattern of Ni/

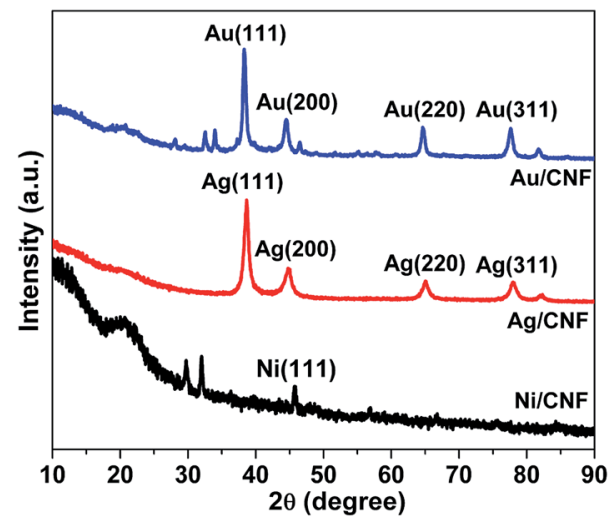

Fig. 4 XRD patterns of Ag/CNF, Au/CNF and Ni/CNF.
CNF confirmed a sharp diffraction peak at around $2 \theta=45.8^{\circ}$, which correspond to the (111) reflection of metallic $\mathrm{Ni}^{22}$

The XPS spectra were taken for m-CNFs, Ag/CNF, Au/CNF and $\mathrm{Ni} / \mathrm{CNF}$; the results are demonstrated in Fig. 5. Two peaks at binding energies $(\mathrm{BE})=\sim 283.1 \mathrm{eV}(\mathrm{C}$ 1s peak) and $\mathrm{BE}=$ $\sim 530.5 \mathrm{eV}$ (O 1s peak) were noticed for all the samples. The $\mathrm{C} 1 \mathrm{~s}$ peak at $\mathrm{BE}=\sim 283.1 \mathrm{eV}$ confirms the presence of $\mathrm{C}-\mathrm{C}, \mathrm{C}-\mathrm{H}, \mathrm{C}-$ $\mathrm{OH}, \mathrm{C}=\mathrm{O}$ and $\mathrm{C}-\mathrm{O}-\mathrm{C}$ groups in the nanofiber composites. Alike, the $\mathrm{O} 1 \mathrm{~s}$ spectra showed the existence of $\mathrm{C}=\mathrm{O}$ and $\mathrm{C}-\mathrm{OH}$ functional groups. ${ }^{23}$ It is very interesting to note that the $\mathrm{C} 1 \mathrm{~s}$ peaks and $\mathrm{O}$ 1s peaks of m-CNFs after metal NPs decoration showed a positive shift in the biding energy. The results indicate that the metal NPs were strongly attached on the surface of the cellulose nanofiber. In the case of $\mathrm{Ag} / \mathrm{CNF}$, the XPS spectrum showed two new peaks at $\mathrm{BE}=367.0 \mathrm{eV}\left(\mathrm{Ag} 3 \mathrm{~d}_{3 / 2}\right)$ and $\mathrm{BE}=$ $373.0 \mathrm{eV}\left(\mathrm{Ag} 3 \mathrm{~d}_{5 / 2}\right)$. Generally, the metallic $\mathrm{Ag}$ appears at $\mathrm{BE}=$ $368.1 \mathrm{eV}\left(\mathrm{Ag} 3 \mathrm{~d}_{3 / 2}\right)$ and $\mathrm{BE}=374.1 \mathrm{eV}\left(\mathrm{Ag} 3 \mathrm{~d}_{5 / 2}\right)$, with $\mathrm{Ag} 3 \mathrm{~d}$ doublet slitting of $6.0 \mathrm{eV} .{ }^{24}$ However, in the present case the peaks shifted toward positive side by $1.1 \mathrm{eV}$ compared to metallic Ag, whereas the slitting of $6.0 \mathrm{eV}$ was maintained. The results confirmed the metallic nature of the $\mathrm{Ag}$ in $\mathrm{Ag} / \mathrm{CNF}$. In case of the $4 \mathrm{f}$ region of $\mathrm{Au} / \mathrm{CNF}$, a doublet $4 \mathrm{f}_{7 / 2}(85.9 \mathrm{eV})$ and $4 \mathrm{f}_{5 /}$ ${ }_{2}(82.2 \mathrm{eV})$ was noticed. This doublet was observed to be shifted toward positive side by $1.9 \mathrm{eV}$ compared to $\mathrm{Au} 4 \mathrm{f}_{7 / 2}$ peak of metallic $\mathrm{Au}(84.0 \mathrm{eV}) .{ }^{25}$ In the $\mathrm{Ni} 2 \mathrm{p}_{3 / 2}$ spectra of Ni/CNF, the peak at $853.4 \pm 0.5 \mathrm{eV}$ corresponding to metallic Ni was noticed. In addition, the satellite peaks at 860.6 and $878.4 \mathrm{eV}$ confirm the presence of small amount of $\mathrm{Ni}^{2+} \cdot{ }^{26}$

\section{Catalytic performance of $\mathrm{Au} / \mathrm{CNF}, \mathrm{Ni} / \mathrm{CNF}$ and $\mathrm{Ag} / \mathrm{CNF}$ composites}

The catalytic activity of $\mathrm{Ag} / \mathrm{CNF}, \mathrm{Au} / \mathrm{CNF}$ and Ni/CNF towards the reduction of 2 - and 4 -NP was tested. The 2 - and 4-NP 
reduction reaction in the presence of $\mathrm{NaBH}_{4}$ is very simple and steady process. However, the reduction process is highly restricted in the absence of metal catalysts due to the high kinetic barrier between the negative ions, nitro group of NP and $\mathrm{BH}_{4}{ }^{-}$ions. Initially, blank reactions without any catalysts were carried out; the results are demonstrated in Fig. 6. The pure 2NP showed a broad band at $\sim 350 \mathrm{~nm}$. Similarly, the 4-NP demonstrated an intense UV adsorption band at $\sim 315 \mathrm{~nm}$. Upon the addition of $\mathrm{NaBH}_{4}$, the adsorption bands of both 4-NP and 2-NP were noticed to be red-shifted due to the formation of nitrophenolate ions (Fig. 6a and b). In the absence of catalyst, the adsorption band of nitrophenolate ions was unchanged even after $24 \mathrm{~h}$. Similarly, the catalytic activity of the fresh mCNFs was also tested. However, it was found to be inactive (Fig. 6c and d).

To our delight, in the presence of $\mathrm{Ag} / \mathrm{CNF}, \mathrm{Au} / \mathrm{CNF}$ and $\mathrm{Ni} /$ CNF, the both 4- and 2-NP reduced very rapidly (Fig. 7-9). The reduction products were confirmed by UV-vis ((Fig. 8 and 9) and UHPLC analysis (Fig. S4-S11 $\dagger$ )). It was found that even a very low amount of catalyst $(0.3,0.6$ and $0.9 \mathrm{mg})$ is enough for the complete reduction of nitrophenols with high reaction rate. The rate of reaction increased with the amount of catalyst and reaction time. The Ni/CNF showed an excellent activity towards the reduction of both 4- and 2-NP. With $0.3 \mathrm{mg}$ of the Ni/CNF, the system required only 9-10 $\mathrm{min}$ for the reduction of both 4- and 2-NP. Increasing the amount of Ni/CNF from $0.3 \mathrm{mg}$ to 0.6 or $0.9 \mathrm{mg}$ showed the rapid reduction of nitrophenols. Especially, with $0.9 \mathrm{mg}$ of catalyst, the Ni/CNF required only 4 to 5 min of the reaction time to achieve the $100 \%$ conversion of 4 and 2-NP to 4- and 2-AP. The reaction kinetics was studied using the time-dependent absorption spectra. The reaction rate is
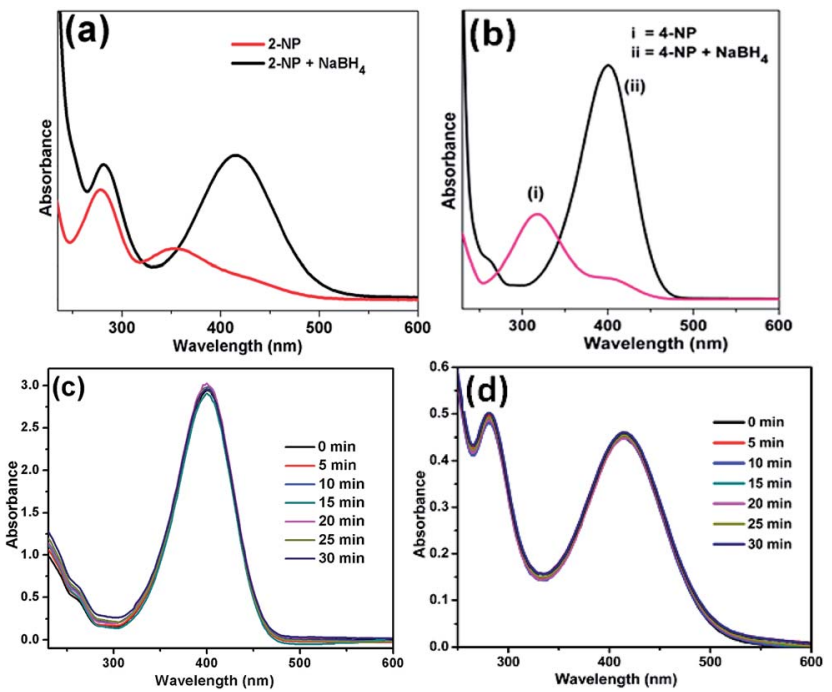

Fig. 6 UV-vis spectra of (a) 2-NP and (b) 4-NP before and after adding $\mathrm{NaBH}_{4}$ solution and the reduction of (c) 4-NP and (d) 2-NP in the presence of $\mathrm{m}$-CNFs recorded every $5 \mathrm{~min}$.

assumed to be independent of $\mathrm{NaBH}_{4}$ concentration due to its excess use. Alike, the adsorption of 2- and 4-NP on m-CNFs can be also ignored due to its inactiveness. The linear correlation between $\ln \left(C_{t} / C_{0}\right)$ and time at $295 \mathrm{~K}$ shows that the reduction of 2- and 4-NP by Ni/CNFs follows the pseudo-first-order reaction kinetics (Fig. 3d and h). The kinetic reaction rate constants $\left(k_{\text {app }}\right)$ were estimated from the slope of the $\ln \left(C_{t} / C_{0}\right)$ versus time liner curve. The $k_{\text {app }}$ values of $2.22,4.69$ and $9.20 \times 10^{-2} \mathrm{~s}^{-1}$ was calculated for the reduction of $4-\mathrm{NP}$ by Ni/CNF with different
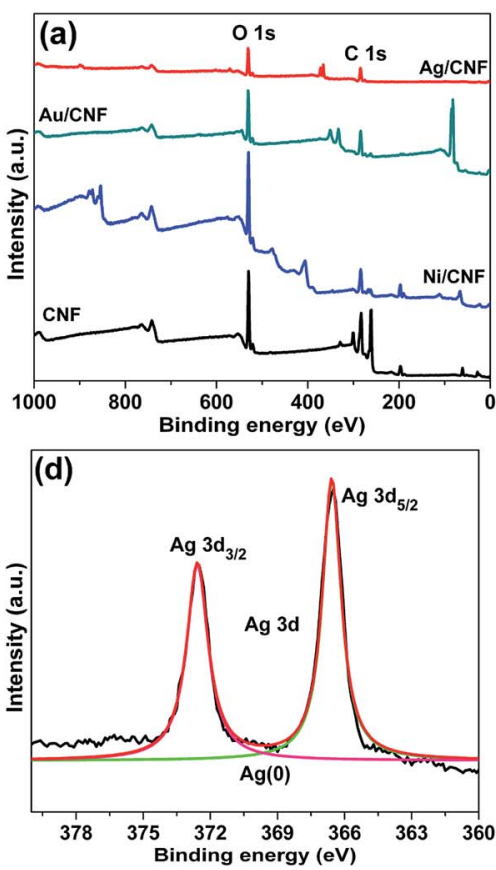
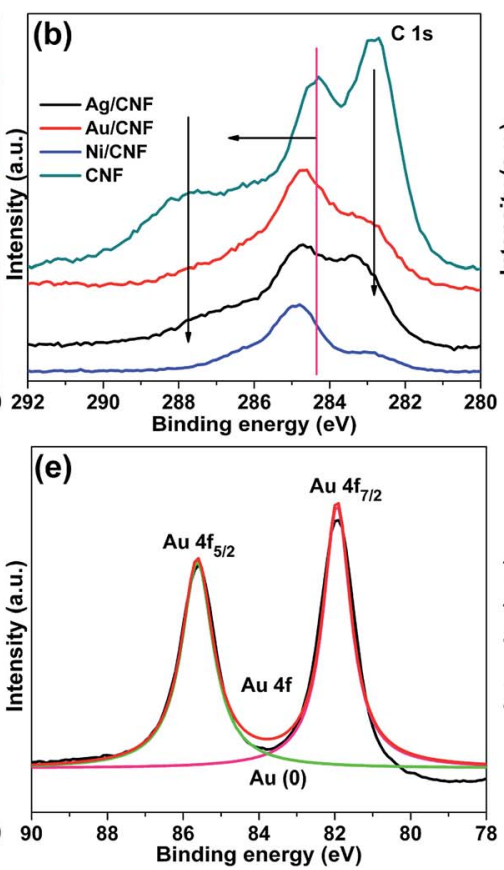
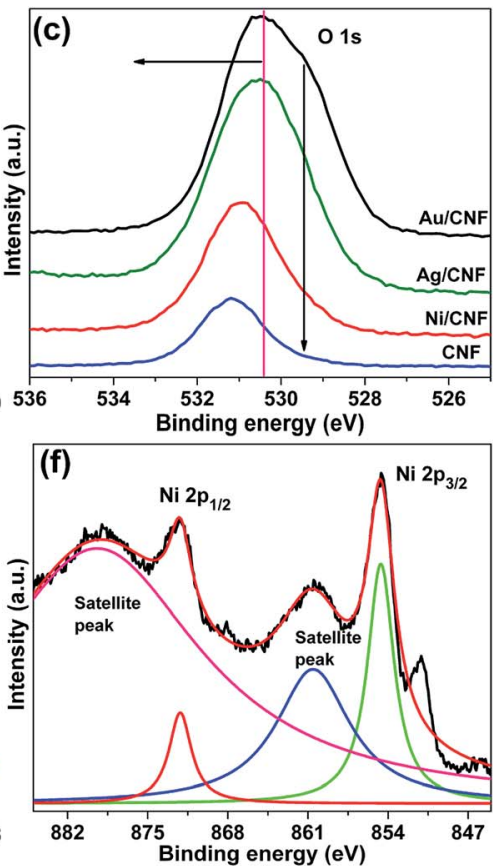

Fig. 5 (a) Survey, (b) C 1s and (c) O 1s XPS spectra of Ag/CNF, Au/CNF and Ni/CNF, and (d) Ag 3d peaks of Ag/CNF, (e) Au 4f peaks of Au/CNF and (f) $\mathrm{Ni} 2 \mathrm{p}$ peaks of Ni/CNF. 

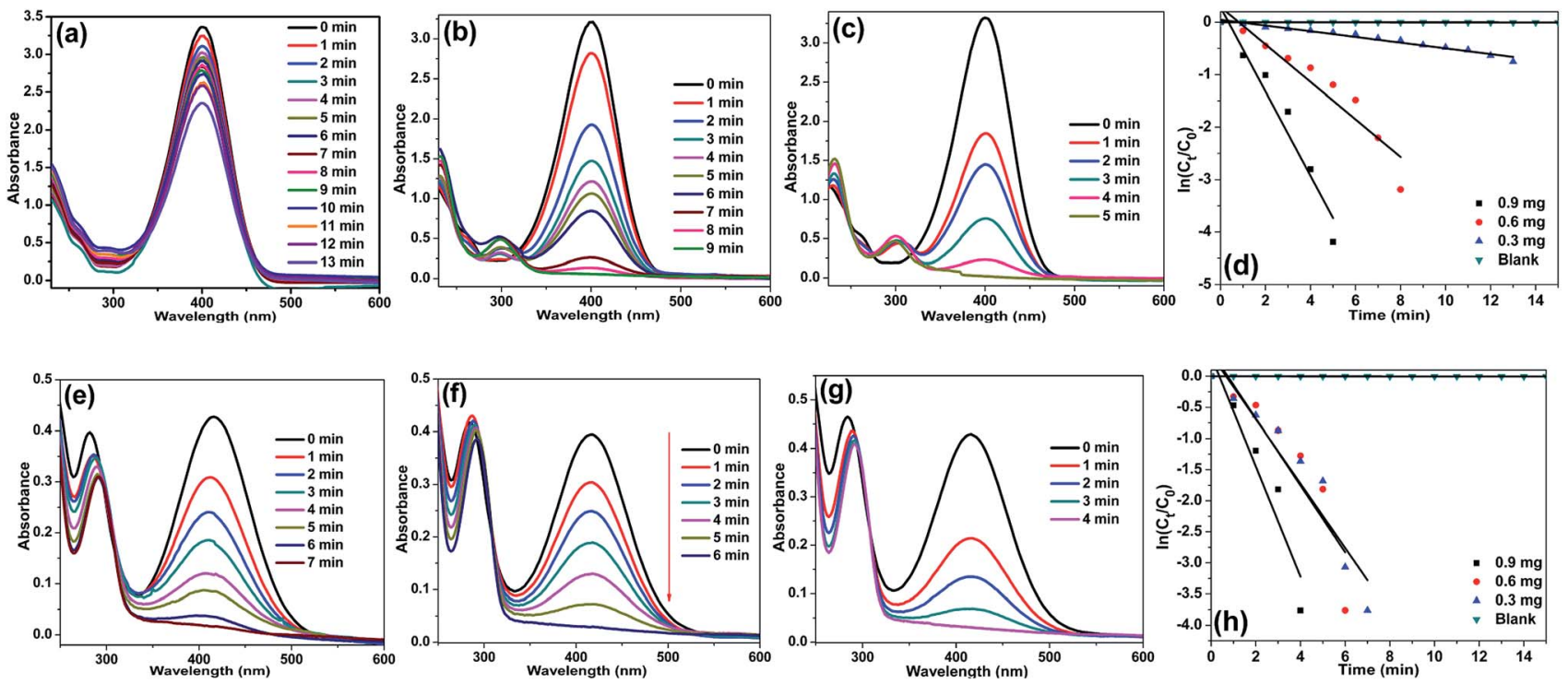

Fig. 7 UV-Vis spectra for the reduction of $(a-c) 4-N P$ and $(e-g) 2-N P$ in aqueous solution recorded every 1 min using different amounts of Ni/ CNF: (a, e) $0.3 \mathrm{mg}$, (b, f) $0.6 \mathrm{mg}$ and $(\mathrm{c}, \mathrm{g}) 0.9 \mathrm{mg}$, and plots of $\ln \left[\mathrm{C}_{t} / \mathrm{C}_{0}\right]$ versus reaction time for reduction of (d) 4-NP and (h) 2-NP with $\mathrm{NaBH} \mathrm{H}_{4}$ over Ni/CNFs.

weights, $0.3,0.6$ and $0.9 \mathrm{mg}$, respectively. In case of the reduction of 2 -NP by Ni/CNF, the $k_{\text {app }}$ values were determined to be $6.44 \times 10^{-2} \mathrm{~s}^{-1}(0.3 \mathrm{mg}), 10.95 \times 10^{-2} \mathrm{~s}^{-1}(0.6 \mathrm{mg})$ and $15.68 \times$ $10^{-2} \mathrm{~s}^{-1}(0.9 \mathrm{mg})$. For a quantitative comparison, the reaction rate constant per unit mass $\left(M_{\text {metal }}\right)$ was calculated by using the equation, the activity parameter $k^{\prime}=k / M$, which is the ratio of the $k_{\text {app }}$ to the weight of the metal active site added. The high $k^{\prime}$ value of $719 \mathrm{~s}^{-1} \mathrm{~g}^{-1}$ (4-NP) and $422 \mathrm{~s}^{-1} \mathrm{~g}^{-1}$ (2-NP) was determined for the reduction of NP using $0.9 \mathrm{mg}$ of Ni/CNF. To the best of our knowledge, this is the most efficient catalyst for the reduction of 2- and 4-NP reported to date. The small Ni NPs size, homogenous distribution of Ni NPs on m-CNFs surface and strong metal-support interaction, are the main key factors for the superior activity of $\mathrm{Ni} / \mathrm{CNF}$. The present $k_{\mathrm{app}}$ values are compared over previously reported heterogeneous catalysts (Table 1). According to the previous reports, the unsupported $\mathrm{Ni}$ NPs require at least $0.5 \mathrm{~h}$ to $3 \mathrm{~h}$ of reaction time for the reduction of 4- and 2-NP under present reaction conditions. ${ }^{27}$ Zhu et al. ${ }^{28}$ prepared of Ni NPs in spherical polyelectrolyte brush nanoreactor (Ni-NPs/SPB) and their catalytic activity towards
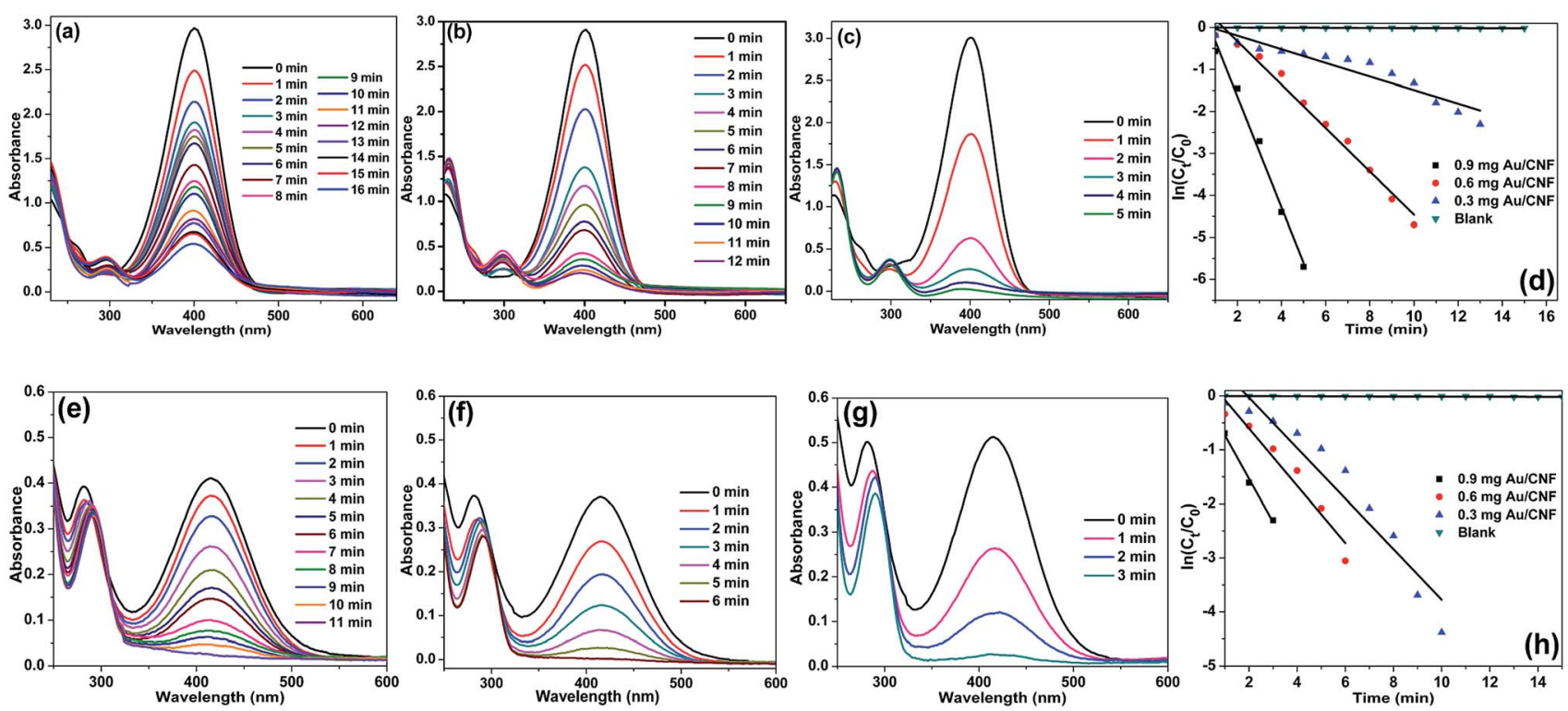

Fig. 8 UV-Vis spectra for the reduction of $(a-c)$ 4-NP and $(e-g) 2-N P$ in aqueous solution recorded every 1 min using different amounts of Au/ CNF: (a, e) $0.3 \mathrm{mg}$, (b, f) $0.6 \mathrm{mg}$ and (c, g) $0.9 \mathrm{mg}$, and plots of $\ln \left[C_{t} / C_{0}\right]$ versus reaction time for reduction of (d) 4-NP and (h) 2-NP with NaBH 4 over Au/CNF. 

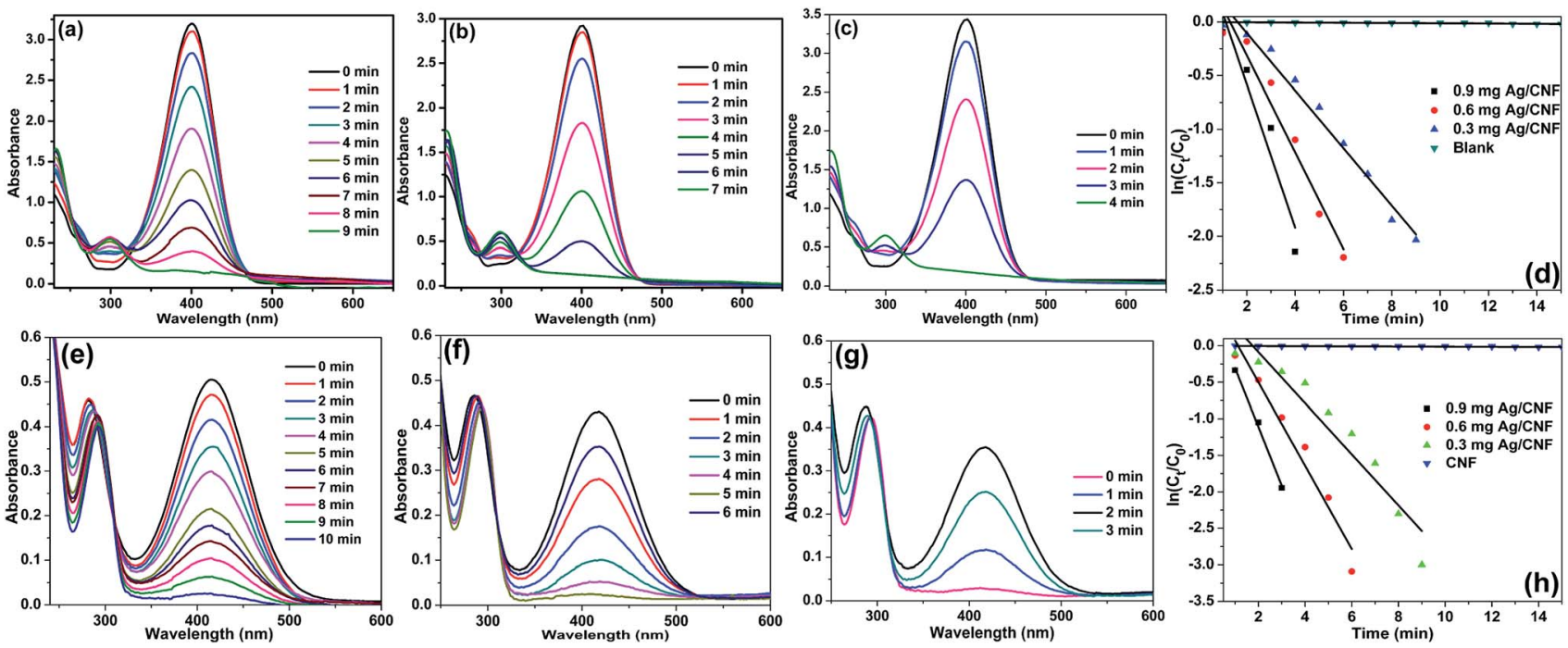

Fig. 9 UV-Vis spectra for the reduction of $(a-c) 4-N P$ and $(e-g) 2-N P$ in aqueous solution recorded every 1 min using different amounts of Ag/ CNF: (a, e) $0.3 \mathrm{mg}$, (b, f) $0.6 \mathrm{mg}$ and (c, g) $0.9 \mathrm{mg}$, and plots of $\ln \left[\mathrm{C}_{t} / \mathrm{C}_{0}\right]$ versus reaction time for reduction of (d) 4-NP and (h) 2-NP with $\mathrm{NaBH} 4$ over Ag/CNF

the reduction of 4-NP. They found that the Ni-NPs/SPB is highly efficient and the rate constant $\left(k_{\text {app }}\right)$ value of $1.56 \times 10^{-4} \mathrm{~s}^{-1}$ was calculated. Similarly, Jiang and co-workers ${ }^{29}$ prepared nano$\mathrm{Ni}$ core mesoporous-silica shell particles $\left(\mathrm{Ni@SiO}{ }_{2}\right)$ for the reduction of 4-NP. The $\mathrm{Ni@SiO}$ system required at least $16 \mathrm{~min}$ for the complete reduction of 4-NP. The maximum $k_{\text {app }}$ value was calculated to be $2.818 \times 10^{-3} \mathrm{~s}^{-1}$. Moreover, nickel nanoparticles supported reduced graphene oxide (Ni-RGO) catalyst ${ }^{30}$ was tested for the reduction of 4-NP and 2-NP under the present reaction conditions (Fig. S12 $\dagger$ ). In comparison to the present $\mathrm{Ni} /$ $\mathrm{CNF}$, the Ni-RGO system required longer reaction time of $9 \mathrm{~min}$ for the complete conversion of 4-NP to 4-AP (with $k_{\text {app }}$ value of $5.57 \times 10^{-3} \mathrm{~s}^{-1}$ ). Similarly, the Ni-RGO system required $7 \mathrm{~min}$ for the reduction of 2-NP to 2-AP and the $k_{\text {app }}$ value was calculated to be $6.33 \times 10^{-3} \mathrm{~s}^{-1}$.

Fig. 8 shows the UV-Vis spectra for the reduction of 4-NP and 2-NP in aqueous solution recorded every $1 \mathrm{~min}$ using different amounts of $\mathrm{Au} / \mathrm{CNF}$. The results confirmed that the $\mathrm{Au} / \mathrm{CNF}$ is highly effective for the reduction of 4- and 2-NP. In the reduction of $4-\mathrm{NP}, 0.3 \mathrm{mg}$ of $\mathrm{Au} / \mathrm{CNF}$ was found to be not enough since the catalytic system could not achieve the complete reduction of 4-NP even after $30 \mathrm{~min}$. However, the complete reduction of 4-NP was attained with $0.6 \mathrm{mg}$ or $0.9 \mathrm{mg}$ of the $\mathrm{Au} /$ CNF. The conversion of 2-NP to 2-AP was also highly effective with low amount of catalyst. The $k_{\text {app }}$ values of $2.15,4.98$ and $9.78 \times 10^{-2} \mathrm{~s}^{-1}$ was determined for the reduction of $4-\mathrm{NP}$ by Au/ CNF with different weights, $0.3,0.6$ and $0.9 \mathrm{mg}$, respectively. In case of the reduction of 2-NP by Au/CNF, the $k_{\text {app }}$ values were calculated to be $6.46 \times 10^{-2} \mathrm{~s}^{-1}(0.3 \mathrm{mg}), 11.56 \times 10^{-2} \mathrm{~s}^{-1}(0.6$ $\mathrm{mg})$ and $12.56 \times 10^{-2} \mathrm{~s}^{-1}(0.9 \mathrm{mg})$. In addition, the reaction rate constant per unit mass $\left(M_{\mathrm{Au}}\right)$ was calculated to be 957 and 1200 $\mathrm{s}^{-1} \mathrm{~g}^{-1}$ for the $\mathrm{Au} / \mathrm{CNF}-$ mediated reduction of 4-NP and 2-NP, respectively. The values (957 and $1200 \mathrm{~s}^{-1} \mathrm{~g}^{-1}$ ) were found to be better when compared to silica supported $\mathrm{Ni@Au} \mathrm{bimetallic}$ catalyst (307 and $237 \mathrm{~s}^{-1} \mathrm{~g}^{-1}$ ) (Table 1). Alike, Zhang et al. ${ }^{31}$ prepared $\mathrm{Au}$ NPs supported electrospun silica nanotubes (AuNPs/SNTs nanocomposite) for the reduction of $p$-nitrophenol. The AuNPs/SNTs nanocomposite reduced the 4-NP within $280 \mathrm{~s}$ with the kinetic constants $k_{\text {app }}$ of $10.64 \times 10^{-3} \mathrm{~s}^{-1}$, which was much higher than other substrate supported $\mathrm{Au}$ nanocatalysts. However, the present cellulose nanocomposites ( $\mathrm{Ni} / \mathrm{CNF}$, the $\mathrm{Au} / \mathrm{CNF}$ and $\mathrm{Ag} / \mathrm{CNF}$ ) showed better catalytic activity than the AuNPs/SNTs nanocomposite. Gold nanoparticles (Au NPs) deposited poly(methyl methacrylate) (PMMA) composites showed that the rate constant and the activation energy are estimated to be $7.2-7.9 \times 10^{-3} \mathrm{~s}^{-1}$ at $295 \mathrm{~K}$ and $38 \mathrm{~kJ} \mathrm{~mol}^{-1}$, respectively. ${ }^{32}$ Magnetically recoverable Au nanocatalyst was employed for the reduction of 4-NP by Chang. The $\mathrm{Au}$ nanocatalyst demonstrated excellent rate constant $k_{\text {app }}$ of $31-78 \times 10^{-2} \mathrm{~m}^{-1}$. $^{32}$ The Au NPs anchored carbon nanotube $(\mathrm{Au} / \mathrm{MWCNTs})^{47}$ catalyst was tested under present reaction conditions (Fig. S13†). However, the Au/MWNCTs did not achieve the complete conversion of 4-NP even after $30 \mathrm{~min}$ of the reaction time. The result confirmed that the cellulose nanofibers are much suitable support for the decoration Au NPs when compared to MWCNTs.

Alike the $\mathrm{Ni} / \mathrm{CNF}$ and $\mathrm{Au} / \mathrm{CNF}, \mathrm{Ag} / \mathrm{CNF}$ also found to highly active toward the reduction of 4- and 2-NP. Fig. 9 shows the adsorption spectra for the reduction of 4- and 2-NP in aqueous solution recorded every 1 min using different amounts of $\mathrm{Ag} /$ CNF. So far, Ag-based nanocatalysts are one of the best catalysts for the reduction of nitrophenols. For example, Ag NPs supported on halloysite nanotubes was prepared and used for the reduction of 4-NP by Liu and co-workers. ${ }^{34}$ Similarly, Agdeposited silica-coated $\mathrm{Fe}_{3} \mathrm{O}_{4}$ magnetic nanoparticle $\left(\mathrm{Fe}_{3} \mathrm{O}_{4} @\right.$ @$\mathrm{SiO}_{2}-\mathrm{Ag}$ ) for the reduction of $p$-nitrophenol was reported by $\mathrm{Du}$ et al. ${ }^{35}$ For the complete reduction of 4-NP, the $\mathrm{Fe}_{3} \mathrm{O}_{4} @ \mathrm{SiO}_{2}-\mathrm{Ag}$ took $14 \mathrm{~min}$ of the reaction time and the $k_{\text {app }}$ value was 
determined to be $0.83-0.68 \mathrm{~min}^{-1}$. Recently, Zhang et al. ${ }^{36}$ prepared AgNPs/electrospun carbon nanofibers (CNFs/AgNPs) for the reduction of $4-\mathrm{NP}$. The minimum time required for the reduction of 4-NP was $8 \mathrm{~min}$ and the $k_{\text {app }}$ value was calculated to be $6.2 \times 10^{-3} \mathrm{~s}^{-1}$ at $295 \mathrm{~K}$. To our delight, the present cellulose nanofiber supported $\mathrm{Ag}$ NPs catalyst $(\mathrm{Ag} / \mathrm{CNF})$ showed better results than the previous reports. In the reduction of 4-NP, $0.6 \mathrm{mg}$ of $\mathrm{Au} / \mathrm{CNF}$ was found to be enough since the catalytic system achieved the complete reduction of 4-NP after only 126 min. When increasing the amount of $\mathrm{Au} / \mathrm{CNF}$ from 0.6 to 0.9, the 4-NP reduced with high rate constant. The time required for the reduction of 4-NP was just $5 \mathrm{~min}$. Similarly, the conversion of 2-NP to 2-AP was also highly effective with low amount of catalyst (Fig. 9e-h). The $k_{\text {app }}$ values of $2.76,4.35$ and $9.05 \times 10^{-2}$ $\mathrm{s}^{-1}$ was determined for the reduction of 4 -NP by Au/CNF with different weights, $0.3,0.6$ and $0.9 \mathrm{mg}$, respectively. In case of the reduction of $2-\mathrm{NP}$ by $\mathrm{Au} / \mathrm{CNF}$, the $k_{\mathrm{app}}$ values were calculated to be $5.67 \times 10^{-2} \mathrm{~s}^{-1}(0.3 \mathrm{mg}), 10.71 \times 10^{-2} \mathrm{~s}^{-1}(0.6 \mathrm{mg})$ and 11.34 $\times 10^{-2} \mathrm{~s}^{-1}(0.9 \mathrm{mg})$. In addition, the reaction rate constant per unit mass $\left(M_{\mathrm{Ag}}\right)$ was calculated to be 395 and $501 \mathrm{~s}^{-1} \mathrm{~g}^{-1}$ for the $\mathrm{Ag} / \mathrm{CNF}$-catalyzed reduction of 4-NP and 2-NP, respectively. In addition, the $\mathrm{Ag}$ /alumina catalyst ${ }^{49}$ was tested for the reduction of 4-NP and 2-NP under the optimized reaction conditions (Fig. S14 $\dagger$ ). The Ag/alumina system required $10 \mathrm{~min}$ for the complete conversion of 4-NP to 4-AP (with $k_{\text {app }}$ value of $5.57 \times$ $10^{-3} \mathrm{~s}^{-1}$ ), whereas the present $\mathrm{Ag} / \mathrm{CNF}$ achieved it in $5 \mathrm{~min}$. In case of the complete reduction of 2-NP to 2-AP, the Ag/alumina required $8 \mathrm{~min}$ whereas the present $\mathrm{Ag} / \mathrm{CNF}$ required just $3 \mathrm{~min}$.

Overall, the present cellulose nanocomposites are found to be highly effective when compared to previously reported systems (refer Table 1). We conclude that the cellulose nanofiber could have provided a better interaction with meal NPs. The other possible reasons for the better catalytic activity are; (1) small size of the metal nanoparticles, (2) strong interaction between metal nanoparticles and support, (3) nature of support and (4) high surface area. To the best of our knowledge, the present cellulose nanocomposites are the most efficient catalysts for the reduction of 4- and 2-NP reported to date (Table 1).

The possible mechanism for the reduction of nitrophenols has been previously reported..$^{\mathbf{4 0 , 4 1}}$ The complete reduction process occurs mainly on the surface of metal NPs supported on the surface of cellulose nanofibers. In the reduction of nitrophenols, $\mathrm{BH}_{4}{ }^{-}$act as donor and the nitro group act as acceptor. In the first step, the nitrophenolate ion adsorbs on the surface of metal

Table 1 Comparison of present cellulose nanocomposites over other heterogeneous catalysts ${ }^{a}$

\begin{tabular}{|c|c|c|c|c|c|c|}
\hline S. no. & Catalyst & Amount of catalyst & Reaction time & Compound & $k_{\text {app }}$ & Reference \\
\hline 1 & Ni-NPs composite brushes & $0.163 \mathrm{mg} \mathrm{L}^{-1}$ & $60 \mathrm{~min}$ & 4-NP & $1 \times 10^{-3} \mathrm{~s}^{-1}$ & 28 \\
\hline 2 & Ni NPs & $90 \mathrm{mg}$ & $16 \mathrm{~min}$ & $4-\mathrm{NP}$ & $2.7 \times 10^{-3} \mathrm{~s}^{-1}$ & 27 \\
\hline 4 & $\mathrm{Ni} / \mathrm{CNF}$ & $0.9 \mathrm{mg}$ & $5 \mathrm{~min}$ & 4-NP & $9.20 \times 10^{-2} \mathrm{~s}^{-1}$ & {$[\#]$} \\
\hline 5 & Fe@Au-ATPGO & $1.8 \mathrm{~g} \mathrm{~L}^{-1}$ & $25 \mathrm{~min}$ & $4-\mathrm{NP}$ & $0.84 \times 10^{-5}\left(\mathrm{~mol} \mathrm{~L}^{-1} \mathrm{~min}^{-1}\right)$ & 37 \\
\hline 6 & Fe@Au-ATPGO & $1.8 \mathrm{~g} \mathrm{~L}^{-1}$ & $25 \mathrm{~min}$ & 2-NP & $0.74 \times 10^{-5}\left(\mathrm{~mol} \mathrm{~L}^{-1} \mathrm{~min}^{-1}\right)$ & 37 \\
\hline 9 & $\mathrm{Au} / \mathrm{PMMA}$ & $3.5 \mathrm{mg}$ & $10 \mathrm{~min}$ & $4-\mathrm{NP}$ & $7.2-7.9 \times 10^{-3} \mathrm{~s}^{-1}$ & 32 \\
\hline 10 & $\mathrm{Au} @ \mathrm{SiO}_{2}$ & - & $60 \mathrm{~min}$ & $4-\mathrm{NP}$ & $4.6 \times 10^{-4} \mathrm{~s}^{-1}$ & 39 \\
\hline 11 & $\mathrm{Au} / \mathrm{CNF}$ & $0.9 \mathrm{mg}$ & $5 \mathrm{~min}$ & 4-NP & $9.05 \times 10^{-2} \mathrm{~s}^{-1}$ & {$[\#]$} \\
\hline 12 & $\mathrm{Au} / \mathrm{CNF}$ & $0.9 \mathrm{mg}$ & $3 \mathrm{~min}$ & 2-NP & $11.34 \times 10^{-2} s^{-1}$ & {$[\#]$} \\
\hline 13 & $\mathrm{Fe}_{3} \mathrm{O}_{4} @ \mathrm{SiO}_{2}-\mathrm{Ag} \mathrm{MNPs}$ & $3 \mathrm{mg}$ & $14 \mathrm{~min}$ & $4-\mathrm{NP}$ & $0.83 \times \min ^{-1}$ & $\begin{array}{l}\left.L^{+}\right] \\
33\end{array}$ \\
\hline 14 & $\mathrm{Ag} /$ carbon fiber & $1.0 \mathrm{mg}$ & 8 min & $4-\mathrm{NP}$ & $4.2 \times 10^{-3} \mathrm{~s}^{-1}$ & 36 \\
\hline 19 & $\mathrm{Ag} / \mathrm{CNF}$ & $0.9 \mathrm{mg}$ & $3 \mathrm{~min}$ & 2-NP & $11.34 \times 10^{-2} s^{-1}$ & {$[\#]$} \\
\hline 20 & Ni NPs-(p(AMPS)) hydrogel & $48 \mathrm{mg}$ & $60 \mathrm{~min}$ & $4-\mathrm{NP}$ & $5.63 \times 10^{-2} \mathrm{~s}^{-1}$ & $\begin{array}{l}{[+1]} \\
42\end{array}$ \\
\hline 21 & Ni NPs-(p(AMPS)) hydrogel & $48 \mathrm{mg}$ & $60 \mathrm{~min}$ & 2-NP & $3.07 \times 10^{-2} \mathrm{~s}^{-1}$ & 42 \\
\hline 22 & Ni@Au/nano-silica & $2 \mathrm{mg}$ & $9.6 \mathrm{~min}$ & $4-\mathrm{NP}$ & $8.3 \times 10^{-3} \mathrm{~s}^{-1}$ & 43 \\
\hline 23 & Ni NPs/silica & $7 \mathrm{mg}$ & $16 \mathrm{~min}$ & $4-\mathrm{NP}$ & $2.818 \times 10^{-3} \mathrm{~s}^{-1}$ & 44 \\
\hline 24 & $\mathrm{Au} /$ graphene & $0.1 \mathrm{mg}$ & $12 \mathrm{~min}$ & $4-\mathrm{NP}$ & $3.17 \times 10^{-3} \mathrm{~s}^{-1}$ & 45 \\
\hline 25 & Au NPs & $6 \mathrm{mg}$ & $13 \mathrm{~min}$ & $4-\mathrm{NP}$ & $2.1 \times 10^{-3} \mathrm{~s}^{-1}$ & 46 \\
\hline 26 & $\mathrm{Au} / \mathrm{MWCNTs}$ & $1 \mathrm{mg}$ & $120 \mathrm{~min}$ & $4-\mathrm{NP}$ & $1.1 \times 10^{-4} \mathrm{~s}^{-1}$ & 47 \\
\hline 27 & $\mathrm{Ag}($ seed $)-\mathrm{SiO}_{2}\left(p-\mathrm{TSA}^{-}\right)$ & $250 \mathrm{mg} \mathrm{L}^{-1}$ & $26 \mathrm{~min}$ & $4-\mathrm{NP}$ & $2.48 \times 10^{-3} \mathrm{~s}^{-1}$ & 48 \\
\hline 28 & $\mathrm{Ag}-\mathrm{NP} / \mathrm{C}$ & $1.0 \mathrm{mg}$ & $25 \mathrm{~min}$ & $4-\mathrm{NP}$ & $1.69 \times 10^{-3} \mathrm{~s}^{-1}$ & 49 \\
\hline 29 & $\mathrm{Ag} /$ alumina & $0.3 \mathrm{mg}$ & $14 \mathrm{~min}$ & $4-\mathrm{NP}$ & $3.2 \times 10^{-3} \mathrm{~s}^{-1}$ & 50 \\
\hline 30 & Ag@AMH & 4 beads & $13 \mathrm{~min}$ & $4-\mathrm{NP}$ & $0.27 \mathrm{~min}^{-1}$ & 51 \\
\hline
\end{tabular}

${ }^{a}[\#]=$ present work. 
catalyst and forms active hydrogen atoms. In the reduction process, the catalytic NPs could acts as an electronic relay system and speed up the electron transfer from $\mathrm{BH}_{4}{ }^{-}$to nitro groups and the catalytic system subsequently gives aminophenols.

\section{Conclusions}

In conclusion, highly active $\mathrm{Au}, \mathrm{Ag}$ and $\mathrm{Ni}$ NPs supported cellulose nanofiber composites (Au/CNF, Ni/CNF and $\mathrm{Ag} / \mathrm{CNF}$ ) were successfully prepared. The resultant nanocomposites demonstrated an excellent catalytic activity towards the reduction of 4- and 2-NP water. Even a very low amount of catalyst (0.6-0.9 mg) was also found to be good enough to achieve $100 \%$ reduction of 4 - and 2 -NP with higher reaction rate (within 5 $\min )$. The present catalyst showed high rate constant $\left(k_{\text {app }}\right)$ and good reaction rate constant per unit mass $\left(k^{\prime}\right)$ values. To the best our knowledge, $\mathrm{Au} / \mathrm{CNF}, \mathrm{Ni} / \mathrm{CNF}$ and $\mathrm{Ag} / \mathrm{CNF}$ are the most efficient nanocatalysts for the reduction of 4- and 2-NP reported to date.

\section{Conflicts of interest}

There are no conflicts of interest to declare.

\section{Acknowledgements}

This study was supported by the Konkuk University KU research professor program. This research was supported by Basic Science Research Program through the National Research Foundation of Korea (NRF) funded by the Ministry of Science, ICT and Future Planning (2015R1A2A1A15051532).

\section{References}

1 K. Oksman, A. Yvonne, P. M. Aji, S. Gilberto, Z. Qi, B. Svetlana, T. Supachok, Z. Xiaojian and H. Saleh, Composites, Part A, 2016, 83, 2-18.

2 S. S. Ray, S. S. Chen, C. W. Li, N. C. Nguyen and H. T. Nguyen, RSC Adv., 2016, 6(88), 85495-85514.

3 H. Bang, K. Watanabe, R. Nakashima, W. Kai, K. H. Song, J. S. Lee, M. Gopiraman and I. S. Kim, RSC Adv., 2014, 4(103), 59571-59578.

4 S. Ramakrishna, F. Kazutoshi, T. Wee-Eong, Y. Thomas, M. Zuwei and R. Ramakrishna, Mater. Today, 2006, 9(3), 40-50.

5 S. Ifuku, M. Tsuji, M. Morimoto, H. Saimoto and H. Yano, Biomacromolecules, 2009, 10(9), 2714-2717.

6 W. K. Son, J. H. Youk and W. H. Park, Carbohydr. Polym., 2006, 65(4), 430-434.

7 T. Zhang, W. Wang, D. Zhang, X. Zhang, Y. Ma, Y. Zhou and L. Qi, Adv. Funct. Mater., 2010, 20(7), 1152-1160.

8 B. Ramaraju, T. Imae and A. G. Destaye, Appl. Catal., A, 2015, 492, 184-189.

9 M. Gopiraman, H. Bang, G. Yuan, C. Yin, K. H. Song, J. S. Lee, I. M. Chung, R. Karvembu and I. S. Kim, Carbohydr. Polym., 2015, 132, 554-564.
10 X. Lin, M. Wu, D. Wu, S. Kuga, T. Endo and Y. Huang, Green Chem., 2011, 13(2), 283-287.

11 T. Ji, L. Chen, M. Schmitz, F. S. Bao and J. Zhu, Green Chem., 2015, 17(4), 2515-2523.

12 Y. C. Chang and D. H. Chen, J. Hazard. Mater., 2009, 165(1), 664-669.

13 P. Zhao, X. Feng, D. Huang, G. Yang and D. Astruc, Coord. Chem. Rev., 2015, 287, 114-136.

14 S. Panigrahi, S. Basu, S. Praharaj, S. Pande, S. Jana, A. Pal, S. K. Ghosh and T. Pal, J. Phys. Chem. C, 2007, 111(12), 4596-4605.

15 M. Gopiraman, S. G. Babu, Z. Khatri, W. Kai, Y. A. Kim, M. Endo, R. Karvembu and I. S. Kim, J. Phys. Chem. C, 2013, 117(45), 23582-23596.

16 M. Gopiraman, A. W. Jatoi, S. Hiromichi, K. Yamaguchi, H. Y. Jeon, I. M. Chung and I. S. Kim, Carbohydr. Polym., 2016, 149, 51-59.

17 K. Yamaguchi, M. Prabakaran, M. Ke, X. Gang, I. M. Chung, I. C. Um, M. Gopiraman and I. S. Kim, Mater. Lett., 2016, 168, 56-61.

18 L. Zhang, T. J. Menkhaus and H. Fong, J. Membr. Sci., 2008, 319(1), 176-184.

19 E. Formo, M. S. Yavuz, E. P. Lee, L. Lane and Y. Xia, J. Mater. Chem., 2009, 19(23), 3878-3882.

20 D. Deng, M. Gopiraman, S. H. Kim, I. M. Chung and I. S. Kim, ACS Sustainable Chem. Eng., 2016, 4(10), 54095414.

21 A. Idris, R. Vijayaraghavan, U. Rana, D. Fredericks, A. Patti and D. MacFarlane, Green Chem., 2013, 15(2), 525-534.

22 M. Gopiraman and I. M. Chung, Korean J. Chem. Eng., 2017, 34(8), 2169-2179.

23 M. Gopiraman, S. G. Babu, Z. Khatri, W. Kai, Y. A. Kim, M. Endo, R. Karvembu and I. S. Kim, J. Phys. Chem. C, 2013, 117(45), 23582-23596.

24 L. Peng, J. Zhang, S. Yang, B. Han, X. Sang, C. Liu, X. Ma and G. Yang, Chem. Commun., 2015, 51, 4398-4401.

25 S. G. Babu, M. Gopiraman, D. Deng, K. Wei, R. Karvembu and I. S. Kim, Chem. Eng. J., 2016, 300, 146-159.

26 M. Gopiraman, D. Deng, K. Q. Zhang, W. Kai, I. M. Chung, R. Karvembu and I. S. Kim, Ind. Eng. Chem. Res., 2017, 56(8), 1926-1939.

27 A. Wang, H. Yin, H. Lu, J. Xue, M. Ren and T. Jiang, Catal. Commun., 2009, 10(15), 2060-2064.

28 Z. Zhu, X. Guo, S. Wu, R. Zhang, J. Wang and L. Li, Ind. Eng. Chem. Res., 2011, 50(24), 13848-13853.

29 Z. Jiang, J. Xie, D. Jiang, J. Jing and H. Qin, CrystEngComm, 2012, 14(14), 4601-4611.

30 Y. Tian, Y. Liu, F. Pang, F. Wang and X. Zhang, Colloids Surf., A, 2015, 464, 96-103.

31 Z. Zhang, S. Changlu, Z. Peng, Z. Peng, Z. Mingyi, M. Jingbo, G. Zengcai, L. Xinghua, W. Changhua and L. Yichun, Chem. Commun., 2011, 47(13), 3906-3908.

32 K. Kuroda, I. Tamao and H. Masatake, J. Mol. Catal. A: Chem., 2009, 298(1), 7-11.

33 X. Du, H. Jiang, Z. Jie, S. Lijuan and A. Songsong, Appl. Surf. Sci., 2012, 258(7), 2717-2723.

34 P. Liu and M. Zhao, Appl. Surf. Sci., 2009, 255(7), 3989-3993. 
35 X. Du, J. He, J. Zhu, L. Sun and S. An, Appl. Surf. Sci., 2012, 258(7), 2717-2723.

36 P. Zhang, S. Changlu, Z. Zhenyi, Z. Mingyi, M. Jingbo, G. Zengcai and L. Yichun, Nanoscale, 2011, 3(8), 3357-3363.

37 V. K. Gupta, N. Atar, M. L. Yola, Z. Ustundag and L. Uzun, Water Res., 2014, 48, 210-217.

38 Y. Yang, Y. Ren, C. Sun and S. Hao, Green Chem., 2014, 16(4), 2273-2280.

39 J. Lee, C. P. Ji and S. Hyunjoon, Adv. Mater., 2008, 20(8), 1523-1528.

40 K. S. Shin, K. C. Young, C. Jeong-Yong and K. Kwan, Appl. Catal., A, 2012, 413, 170-175.

41 B. Naik, H. Subhenjit, S. P. Vadakkethonippurathu and N. G. Narendra, Catal. Commun., 2011, 12(12), 1104-1108.

42 J. Liu, J. Wang, Y. Wang, C. Liu, M. Jin, Y. Xu, L. Li, X. Guo, A. Hu, T. Liu, S. F. Lincoln and R. K. Prudhomme, Colloid Interface Sci. Commun., 2015, 4, 1-4.

43 X. Le, Z. Dong, W. Zhang, X. Li and J. Ma, J. Mol. Catal. A: Chem., 2014, 395, 58-65.

44 Z. Jiang, J. Xie, D. Jiang, J. Jing and H. Qin, CrystEngComm, 2012, 14(14), 4601-4611.
45 J. Li, C. Y. Liu and Y. Liu, J. Mater. Chem., 2012, 22(17), 84268430.

46 H. Rashid, R. R. Bhattacharjee, A. Kotal and T. K. Mandal, Langmuir, 2006, 22(17), 7141-7143.

47 T. M. Abdel-Fattah and A. Wixtrom, ECS J. Solid State Sci. Technol., 2014, 3(4), M18-M20.

48 N. Muthuchamy, A. Gopalan and K. P. Lee, RSC Adv., 2015, 5(93), 76170-76181.

49 S. Tang, S. Vongehr and X. Meng, J. Phys. Chem. C, 2010, 114(2), 977-982.

50 B. Naik, V. S. Prasad and N. N. Ghosh, Powder Technol., 2012, 232, 1-6.

51 L. Ai, H. Yue and J. Jiang, J. Mater. Chem., 2012, 22(44), 23447-23453.

52 S. Saravanamoorthy, I. M. Chung, V. Ramkumar, R. Baskar and M. Gopiraman, J. Ind. Eng. Chem., 2017, DOI: 10.1016/ j.jiec.2017.10.006.

53 M. Gopiraman, S. Saravanamoorthy and I. M. Chung, Res. Chem. Intermed., 2017, 43(10), 5601-5614.

54 M. Gopiraman and I. M. Chung, Korean J. Chem. Eng., 2017, 34(8), 2169-2179. 